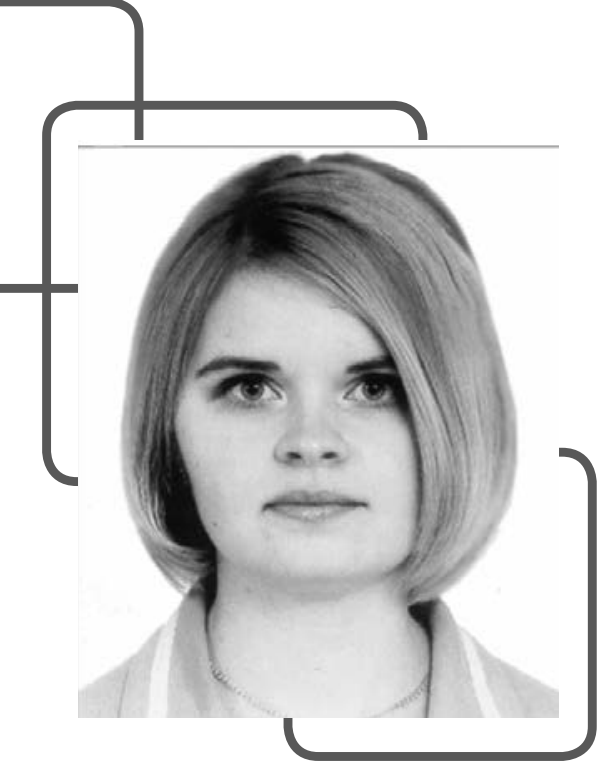

Биологически активные вещества, экстракция, цветки пижмы обыкновенной, лекарственное растительное сырьё, цинарозид

\section{Biologically active} substances, extraction, Tanacetum vulgare flowers, medicinal plant raw materials, cinaroside
Научная статья

УДК 619:615.32:582.998

doi:10.35694/YARCX.2021.55.3.007

\section{СПОСОБ ОПРЕДЕЛЕНИЯ СУММЫ ФЛАВОНОИДОВ В ЦВЕТКАХ ПИЖМЫ ОБЫКНОВЕННОЙ}

\author{
Ю. Г. Соболева (фото) \\ канд. ветеринар. наук, доцент, доцент кафедры химии \\ И. Ю. Постраш \\ канд. биол. наук, доцент, доцент кафедры химии \\ А. А. Прусакова \\ ассистент кафедры химии \\ УО «Витебская государственная ордена «Знак Почета» \\ академия ветеринарной медицины», г. Витебск, \\ Республика Беларусь
}

В настоящее время, несмотря на высокий уровень промышленного производства синтетических лекарственных препаратов, спрос на лекарственные средства природного происхождения остаётся неизменно высоким как в Республике Беларусь, так и в других странах.

Препараты растительного происхождения, как правило, обладают широким спектром действия на организм, хорошей переносимостью и малой токсичностью в терапевтических дозах.

Одно из лекарственных растений, являющихся источником создания высокоэффективных лекарственных средств - пижма обыкновенная (Tanacetum vulgare L.). Это многолетнее травянистое растение из семейства Астровые (Asteraceae). В качестве лекарственного растительного сырья (ЛРС) заготавливают соцветия пижмы, которые собирают в начале цветения. Цветочные корзинки растения содержат значительное количество флавоноидных соединений (лютеолин, апигенин, акацетин, кверцетин, цинарозид), эфирные масла, в состав которых входят в основном бициклические монотерпеноиды: $\beta$-туйон, а-туйон, камфора, борнеол, пинен, фенольные кислоты, дубильные вещества, горечи и др. В пижме кумулируются цинк, молибден, селен и др. $[1 ; 2]$.

Препараты пижмы оказывают противопаразитарное, желчегонное, спазмолитическое, вяжущее действие. Они повышают аппетит, кислотность желудочного сока, улучшают переваривание пищи, положительно влияют на обменные функции печени, оказывают бактерицидное действие. В качестве желчегонных средств препараты пижмы используют при холециститах, холангитах, энтероколитах [3].

В ветеринарии цветки пижмы применяют внутрь в виде настоя, порошка и экстракта при паразитозах животных. Экстракт цветков обладает хорошим антигельминтным действием при аскаридозах, стронгилятозах желудочно-кишечного тракта лошадей, крупного рогатого скота и собак. Наружно растение используют для лечения гнойных язв, ран, чесотки [3]. 
Вопросы стандартизации сырья лекарственных растений и фитопрепаратов, содержащих флавоноиды, достаточно актуальны, поскольку во многих методиках используются различные подходы к исследованию их качественного и количественного состава $[2 ; 4 ; 5]$. Основными методами извлечения биологически активных веществ из ЛРС являются методы экстракции, которые приводят к накоплению необходимых биологически важных компонентов в определённом экстрагенте. В зависимости от природы экстрагента, его количества, времени экстракции, температуры и других факторов из одного и того же сырья могут быть получены композиции биологически активных веществ с разным химическим составом [5; 6; 7].

Цель наших исследований - оптимизация существующих методов стандартизации растительного сырья пижмы обыкновенной. Для этого мы изучали влияние концентрации экстрагента и времени экстракции на полноту извлечения суммы флавоноидов цветков пижмы обыкновенной.

\section{Материалы и методы}

Исследования проводились в лаборатории кафедры химии УО «Витебская государственная ордена «Знак Почета» академия ветеринарной медицины». Материалом для анализа были цветки пижмы обыкновенной, собранные в окрестностях г. Витебска (Республика Беларусь).

Для эксперимента в качестве экстрагирующего вещества нами выбран этиловый спирт 96- и 70\%-й концентрации.

Сырьё пижмы обыкновенной измельчали до частиц, проходящих сквозь сито с отверстиями диаметром 1 мм. Для исследования брали навеску измельчённого сырья цветков пижмы массой 1,000 г и помещали её в плоскодонную колбу вместимостью 100 мл со шлифом, прибавляли этиловый спирт. Экстракцию проводили этанолом в соотношении сырьё/экстрагент 1:50, 1:100. Время экстрагирования составляло 30 и 60 минут. Извлечение фильтровали через бумажный фильтр «синяя лента».

По данным ряда авторов, флавоноиды пижмы близки по значениям спектральных характеристик к государственному стандартному образцу (ГСО) цинарозида [2; 5].

Определение суммы флавоноидов в пересчёте на цинарозид проводили спектрофотометрически. Для анализа использовали реакцию комплексообразования флавоноидов с 3\%-м раствором алюминия хлорида для исключения вклада в значение оптической плотности других групп соединений, в частности гидроксикоричных кислот (метод дифференциальной спектрофотометрии) [2; 5]. В качестве раствора сравнения использовали раствор, приготовленный при тех же условиях, но без добавления алюминия хлорида. Параллельно изме- ряли оптическую плотность раствора ГСО цинарозида, приготовленного по аналогии с испытуемым раствором.

Регистрацию спектров проводили на спектрофотометре «СОЛАР UV-VIS PB 2201» в пределах длин волн 300-450 нм.

\section{Результаты исследований}

При использовании метода дифференциальной спектрофотометрии для анализа водно-спиртовых извлечений из цветков пижмы обыкновенной наблюдался батохромный сдвиг длинноволновой полосы флавоноидов, который проявился в виде максимума поглощения при длине волны 450 нм.

При изучении спектральных характеристик ГСО цинарозида аналогичным методом нами установлено, что его раствор в присутствии алюминия хлорида имеет тот же максимум поглощения (425 нм). В связи с этим, в качестве метода количественного анализа для стандартизации ЛРС пижмы обыкновенной в дальнейшем мы использовали дифференциальную спектрофотометрию для определения суммы флавоноидов в пересчёте на цинарозид. Расчёт проводили предложенным ранее методом [8].

Спектральные характеристики водно-спиртовых извлечений из цветков пижмы обыкновенной 70\%-м этиловым спиртом (экстрагирование в течение 30 минут) представлены на рисунке 1.

При данных условиях наблюдаются самые высокие показатели оптической плотности в соотношениях сырьё/экстрагент 1:50 и 1:100.

Нами экспериментально установлено, что аналогичное экстрагирование в течение 60 минут даёт гораздо меньшие значения оптической плотности (рис. 2).

Из графика видно, что при двух различных соотношениях сырьё/экстрагент и выдержке 60 минут максимум спектра поглощения приходится на 425 нм, значения оптической плотности находятся в пределах от 0,6 до 0,7. Экстрагирование менее 30 минут нецелесообразно, а максимум спектра поглощения при различных условиях экстракции остаётся неизменным - 425 нм.

Спектральные характеристики водно-спиртовых извлечений из цветков пижмы обыкновенной 96\%-м этиловым спиртом представлены на рисунках 3 и 4 (экстрагирование в течение 30 и 60 минут соответственно).

В данном случае (рис. 3) значения оптической плотности невысокие, прослеживается прямая их зависимость от соотношения сырьё/экстрагент.

Как видно из рисунков 3 и 4, использование в качестве экстрагента 96\%-го раствора спирта этилового приводит к неполному высвобождению флавоноидных соединений из лекарственного растительного сырья пижмы - цветков. 


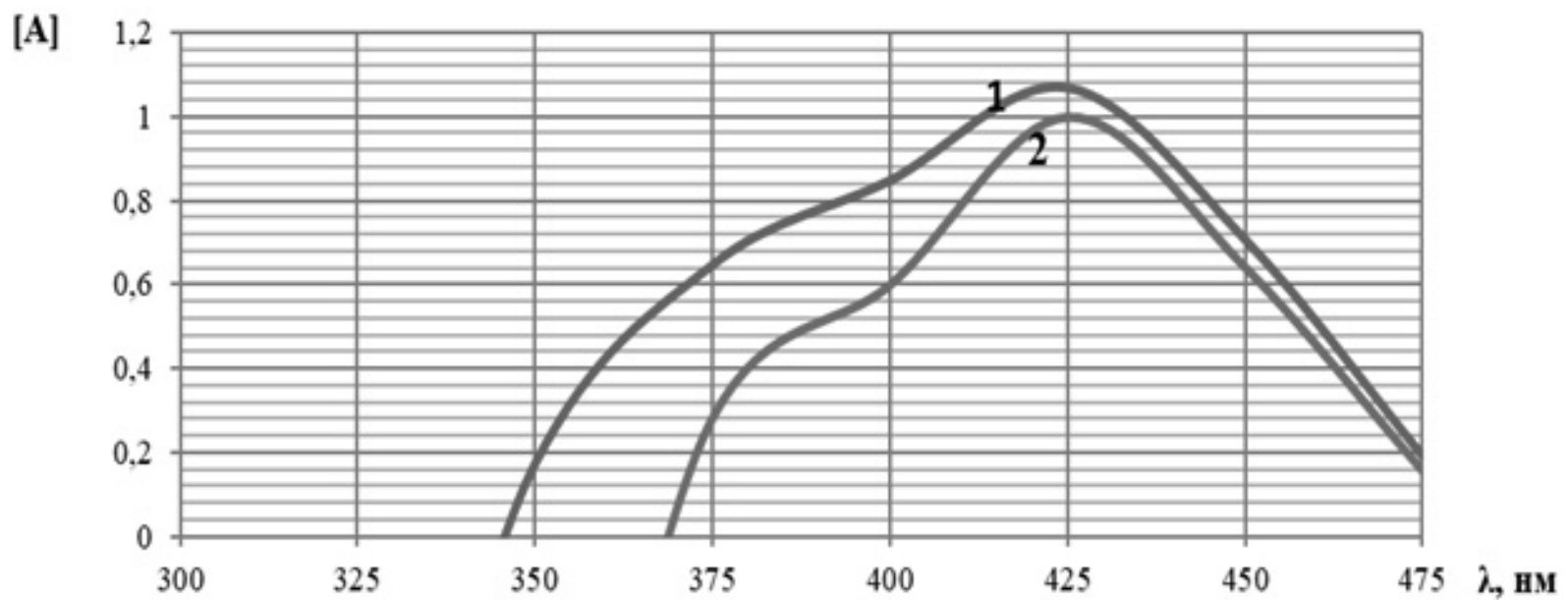

1 - соотношение сырьё/экстрагент 1:50; 2 - соотношение сырьё/экстрагент 1:100.

Рисунок 1 - Оптическая плотность растворов (этиловый спирт 70\%, экстрагирование в течение 30 минут)

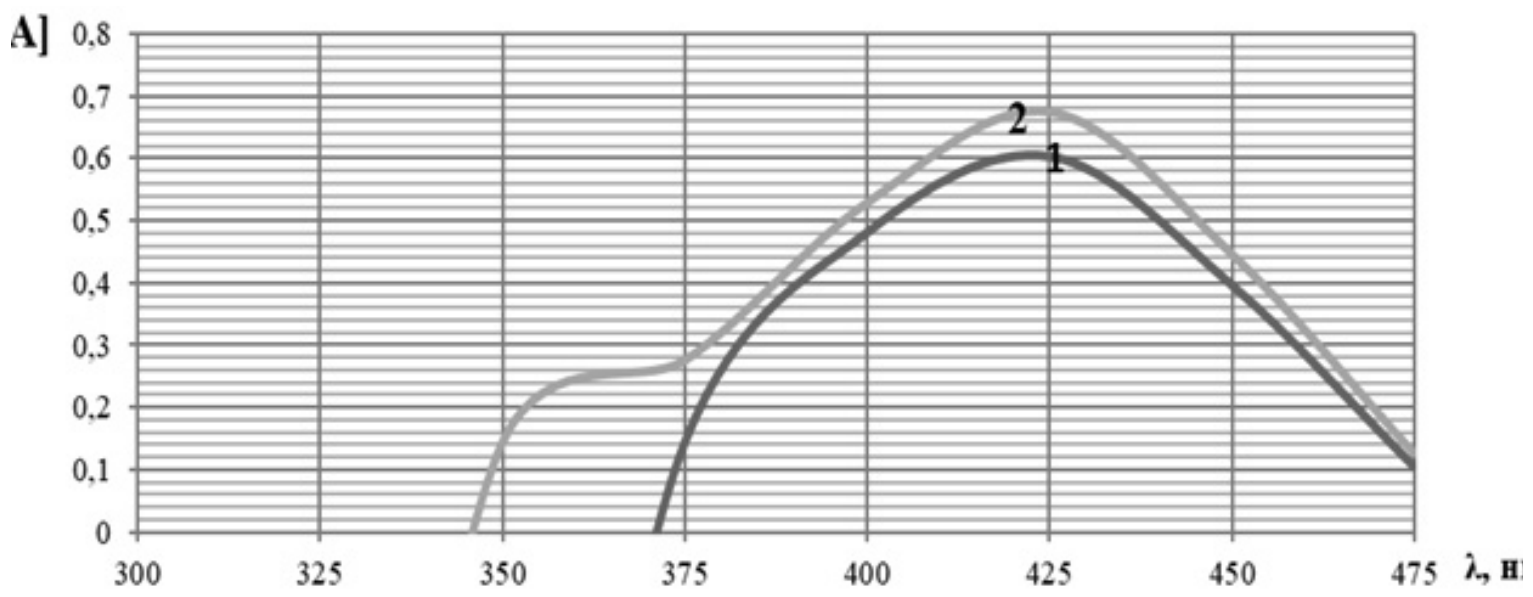

1 - соотношение сырьё/экстрагент 1:50; 2 - соотношение сырьё/экстрагент 1:100.

Рисунок 2 - Оптическая плотность растворов (этиловый спирт 70\%, экстрагирование в течение 60 минут)

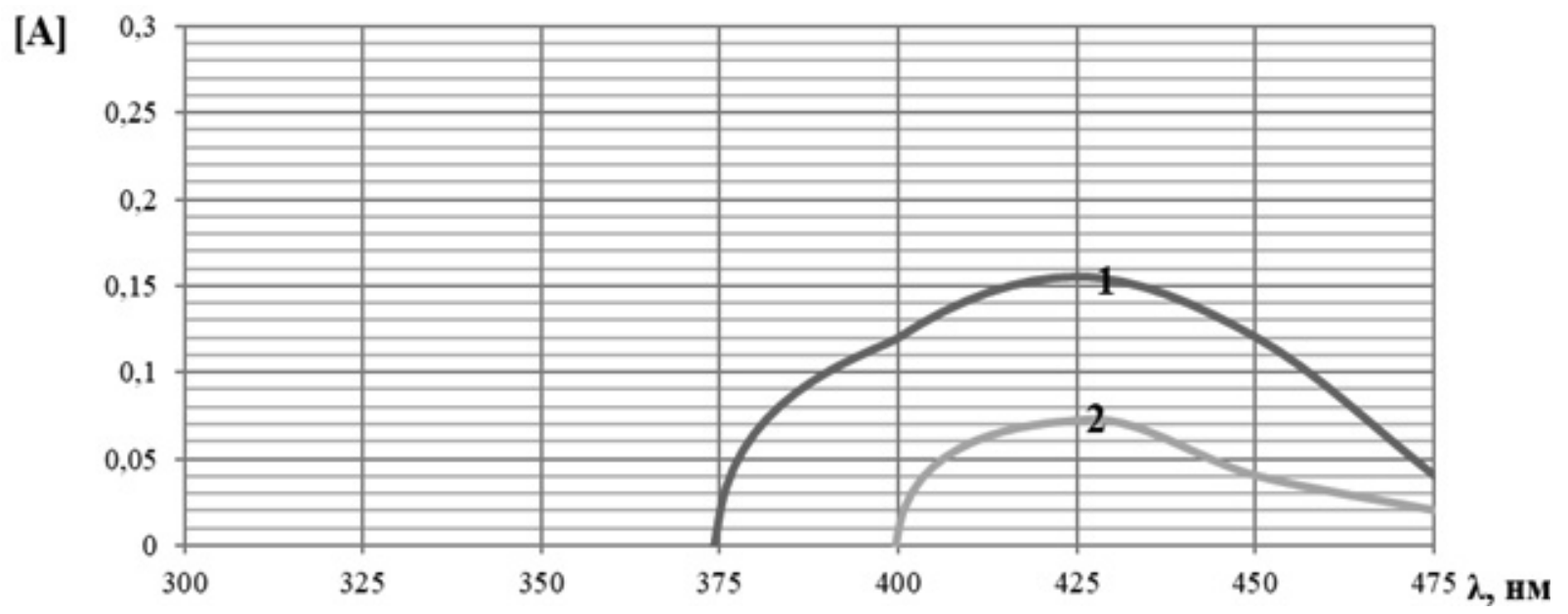

1 - соотношение сырьё/экстрагент 1:50; 2 - соотношение сырьё/экстрагент 1:100.

Рисунок 3 - Оптическая плотность растворов (этиловый спирт 96\%, экстрагирование в течение 30 минут) 


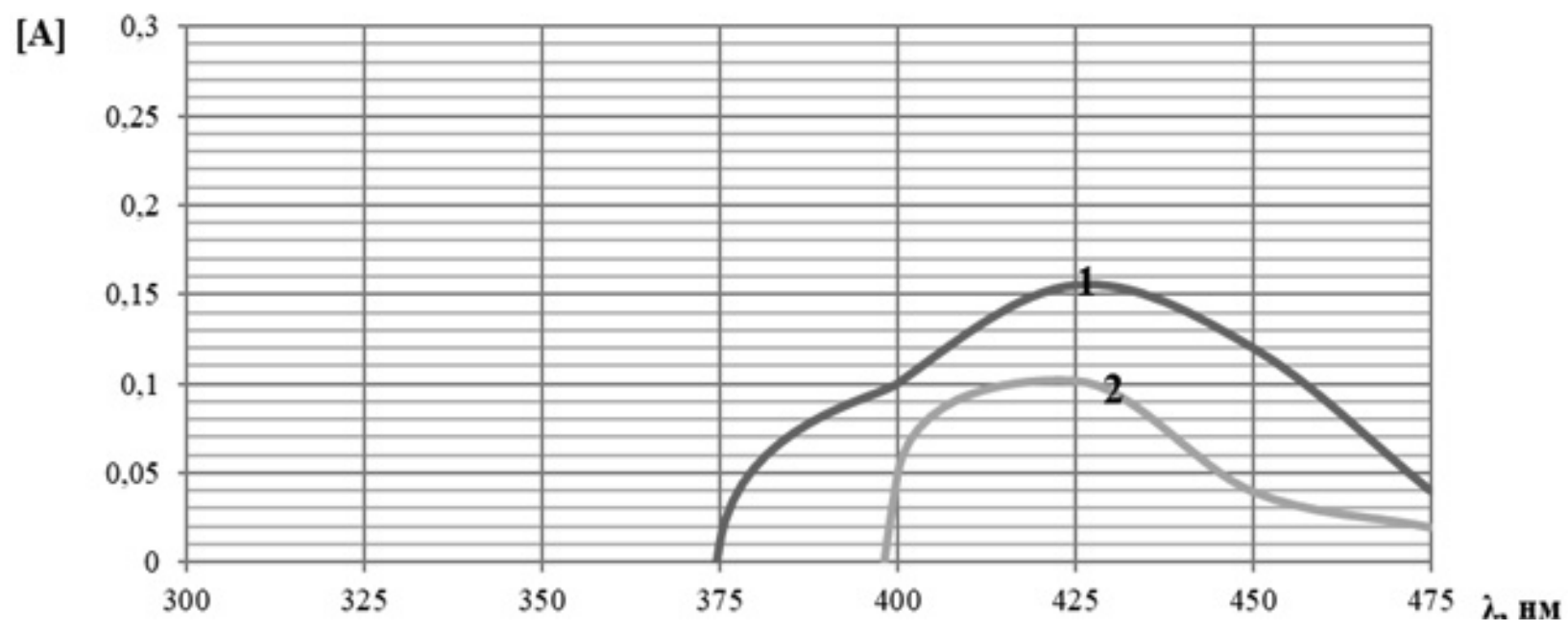

1 - соотношение сырьё/экстрагент 1:50; 2 - соотношение сырьё/экстрагент 1:100.

Рисунок 4 - Оптическая плотность растворов (этиловый спирт 96\%, экстрагирование в течение 60 минут)

Прослеживается обратная зависимость времени экстрагирования растительного сырья к содержанию флавоноидов (в \%) в водно-спиртовой вытяжке (рис. 5).
Таким образом, можно сделать заключение, что использование 96\%-го раствора спирта в качестве экстрагента экономически не выгодно, так как он не даёт максимального извлечения фла-

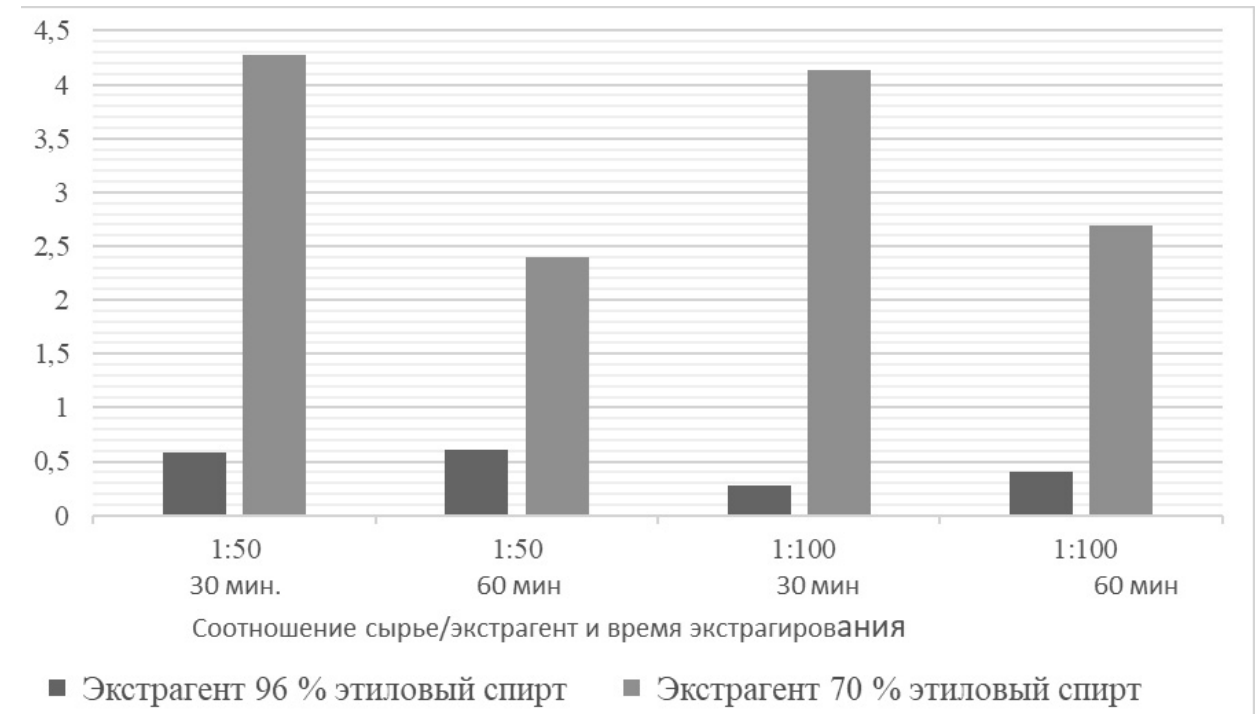

Рисунок 5 - Влияние времени и условий экстракции на полноту извлечения суммы флавоноидов (в \%) из цветков пижмы обыкновенной

воноидов. В качестве оптимального экстрагента нами выбран 70\%-й этиловый спирт (вместо 95\% спирта этилового, используемого в фармакопейной методике). Экстрагирование в течение 30 минут наиболее эффективно, что значительно сокращает время анализа, предложенное ранее.

Соотношение сырьё/экстрагент 1:50 считаем наиболее подходящим, так как это также снижает затраты на проведение количественного анализа сырья пижмы обыкновенной. На наш взгляд, наиболее целесообразно использовать в методике ко- личественного анализа дифференциальную спектрофотометрию при длине аналитической волны 425 нм и ГСО цинарозида.

\section{Выводы}

Проблема объективной стандартизации сырья лекарственных растений и фитопрепаратов, содержащих флавоноиды, в настоящий момент достаточно актуальна, так как во многих методиках используются различные подходы к исследованию качественного и количественного состава. 
На основании проведённых нами исследований для определения суммы флавоноидов в цветках пижмы обыкновенной мы предлагаем использовать в качестве экстрагента раствор 70\% этилового спирта для получения водно-спиртовых извлечений в режиме однократной экстрак- ции. Оптимальным сочетанием сырьё/экстрагент является массовое соотношение 1:50, продолжительность экстракции 30 минут с последующим использованием дифференциальной спектрофотометрии и ГСО цинарозида при длине волны $425 \mathrm{HM}$.

\section{Список источников}

1. Кулагин, О. Л. Антиоксидантная активность некоторых фитопрепаратов, содержащих флавоноиды и фенилпропаноиды / О. Л. Кулагин, В. А. Куркин, Н. С. Додонов [и др.]. - Текст : непосредственный // Фармация. - 2007. - Т. 55, № 2. - С. 30-32. - ISSN 0367-3014.

2. Куркина, А. В. Актуальные аспекты стандартизации сырья и препаратов пижмы обыкновенной / А. В. Куркина, А. И. Хусаинова. - Текст : непосредственный // Медицинский альманах. - 2010. - № 2 (11). C. 322-326. - ISSN 1997-7689.

3. Ятусевич, А. И. Теоретические и практические основы применения лекарственных растений при паразитарных болезнях животных / А. И. Ятусевич [и др.]. - Витебск : ВГАВМ, 2011. - 90 с. - Текст : непосредственный. - ISBN 978-985-512-493-2.

4. Куркин, В. А. Проблемы стандартизации растительного сырья и препаратов, содержащих фенилпропаноиды / В. А. Куркин, Е. В. Авдеева. - Текст : непосредственный // Фармация. - 2009. - № 1. - С. 51-54. ISSN 0367-3014.

5. Куркина, А. В. Актуальные аспекты стандартизации лекарственного растительного сырья, содержащего флавоноиды / А. В. Куркина. - Текст : непосредственный // Бюллетень сибирской медицины (Bulletin of Siberian medicine). - 2011. - T. 10, № 5. - C. 150-153. - ISSN 1682-0363.

6. Постраш, И. Ю. Экстракция биологически активных веществ из цветков ромашки аптечной / И. Ю. Постраш, Ю. Г. Соболева, В. С. Андрущенко. - Текст : непосредственный // Вестник АПК Верхневолжья. - 2020. - № 1 (49). - С. 22-26. - ISSN 1998-1635.

7. Постраш, И. Ю. Трава зверобоя продырявленного: химический состав, свойства, применение / И. Ю. Постраш. - Текст : непосредственный // Вестник АПК Верхневолжья. - 2021. - № 1 (53). - С. 57-63. ISSN 1998-1635.

8. Куркина, А. В. Методика определения суммы флавоноидов в цветках пижмы / А. В. Куркина, А. И. Хусаинова. - Текст : непосредственный // Фармация. - 2010. - Т. 58, № 3. - С. 21-24. - ISSN 0367-3014.

\section{References}

1. Kulagin, O. L. Antioksidantnaja aktivnost' nekotoryh fitopreparatov, soderzhashhih flavonoidy i fenilpropanoidy / O. L. Kulagin, V. A. Kurkin, N. S. Dodonov [i dr.]. - Tekst : neposredstvennyj // Farmacija. 2007. - T. 55, № 2. - S. 30-32. - ISSN 0367-3014.

2. Kurkina, A. V. Aktual'nye aspekty standartizacii syr'ja i preparatov pizhmy obyknovennoj / A. V. Kurkina, A. I. Khusainova. - Tekst : neposredstvennyj // Medicinskij al'manah. - 2010. - № 2 (11). - S. 322-326. - ISSN 1997-7689.

3. Yatusevich, A. I. Teoreticheskie i prakticheskie osnovy primenenija lekarstvennyh rastenij pri parazitarnyh boleznjah zhivotnyh / A. I. Yatusevich [i dr.]. - Vitebsk : VGAVM, 2011. - 90 s. - Tekst : neposredstvennyj. - ISBN 978-985-512-493-2.

4. Kurkin, V. A. Problemy standartizacii rastitel'nogo syr'ja i preparatov, soderzhashhih fenilpropanoidy / V. A. Kurkin, E. V. Avdeeva. - Tekst : neposredstvennyj // Farmacija. - 2009. - № 1. - S. 51-54. - ISSN 0367-3014.

5. Kurkina, A. V. Aktual'nye aspekty standartizacii lekarstvennogo rastitel'nogo syr'ja, soderzhashhego flavonoidy / A. V. Kurkina. - Tekst : neposredstvennyj // Bjulleten' sibirskoj mediciny (Bulletin of Siberian medicine). 2011. - T. 10, № 5. - S. 150-153. - ISSN 1682-0363.

6. Postrash, I. Yu. Jekstrakcija biologicheski aktivnyh veshhestv iz cvetkov romashki aptechnoj / I. Yu. Postrash, Yu. G. Soboleva, V. S. Andrushchenko. - Tekst : neposredstvennyj // Vestnik APK Verhnevolzh'ja. - 2020. - № 1 (49). - S. 22-26. - ISSN 1998-1635.

7. Postrash, I. Yu. Trava zveroboja prodyrjavlennogo: himicheskij sostav, svojstva, primenenie / I. Yu. Postrash. - Tekst : neposredstvennyj // Vestnik APK Verhnevolzh'ja. - 2021. - № 1 (53). - S. 57-63. - ISSN 1998-1635.

8. Kurkina, A. V. Metodika opredelenija summy flavonoidov v cvetkah pizhmy / A. V. Kurkina, A. I. Khusainova. Tekst : neposredstvennyj // Farmacija. - 2010. - T. 58, № 3. - S. 21-24. - ISSN 0367-3014. 